\title{
BLDC Motor Control Optimization Using Optimal Adaptive PI Algorithm
}

\author{
Supriyanto Praptodiyono a, Hari Maghfiroh ${ }^{\text {b, * }}$, Chico Hermanu ${ }^{\text {b }}$ \\ ${ }^{a}$ Departement of Electrical Engineering \\ Universitas Sultan Ageng Tirtayasa (UNTIRTA) \\ Jl. Jendral Sudirman Km.3, Kotabumi \\ Cilegon, Indonesia \\ ${ }^{b}$ Departement of Electrical Eangineering \\ Sebelas Maret University (UNS) \\ Jl. Ir. Sutami 36A, Jebres \\ Surakarta, Indonesia
}

\begin{abstract}
The main problem of using a Proportional Integral (PI) Controller in Brushless Direct Current (BLDC) motor speed control is tuning the PI's parameter and its performance cannot adapt to the system behavior changes. Particle Swarm Optimization (PSO) has been chosen to optimize the tuning. Fuzzy Logic Controller (FLC) is used to online tuning PI's parameters to adapt to system conditions. Optimal adaptive PI, which combines the PSO method and FLC method to tune PI, is proposed. It was successfully implemented in the simulation environment. The test was carried out in three conditions: step responses, set-point changes, and disturbance rejection. The proposed algorithm is superior with no overshoot/undershoot. Whereas in terms of settling time is in between PI and PI-PSO. PI controller has the smallest control effort. However, the other parameter is the worst. PI-PSO is superior in terms of settling time and Integral of Absolute Error (IAE) except for the step response test. The proposed method has lower IAE and higher control effort by $78.73 \%$ and $60 \%$ compared to PI control. On the other hand, it has a higher IAE dan lower control effort by $11.82 \%$ and $33.88 \%$ compared to PI-PSO. Therefore, the optimal adaptive PI control can reduce energy consumption compared to optimal PI with better performance than PI control.
\end{abstract}

Keywords: PID, fuzzy, optimal, adaptive, control, motor, BLDC

\section{INTRODUCTION}

The control system that is widely used in industry is PID (Proportional Integral Derivative). Based on [1], [2], almost $90 \%$ of industries still use PID control because of its simplicity, applicability, and reliability. However, PID's weakness is that it takes a long time to tune [3], [4]. Several methods of tuning PID controls have been proposed. This tuning method can be categorized into i) empirical methods such as Ziegler-Nichols (ZN) and Cohen-Coon (CC), ii) analytical methods such as root locus (RL) and frequency response (FR), and iii) optimization methods such as using Genetic Algorithm (GA), Particle Swarm Optimization (PSO), and Ant Colony Optimization (ACO) [2], [4], [5]. The optimization method is now widely used because of its ability to optimize the performance of PID controls as in [6], [7].

The Brushless Direct Current (BLDC) motor is commonly used in industrial applications and electric vehicles [8]. It is superior compared to conventional brushed DC motor due to attractive features such as high efficiency, high torque, great speed, small noise, small volume, and extended life [9]. In the 1990s, several conventional linear controllers such as Proportional Integral (PI), Proportional Derivative (PD), and PID are

\footnotetext{
* Corresponding Author.

Email: hari.maghfiroh@staff.uns.ac.id

Received: October 29, 2020 ; Revised: November 23, 2020

Accepted: November 30, 2020 ; Published: December 31, 2020

(C) 2020 PPET - LIPI
}

used to control BLDC motor [10]. However, since the BLDC motor is a multivariable, nonlinear, and strong coupling complex system [11]. Therefore, it required a variable-speed operation in which the PI controller is unable to handle due to its limitation in a single operating point, whereas PD and PID are usually avoided in power electronics because of their tendency to amplify the ripple [12].

When using PID as speed control of BLDC motor, two problems are tuning PID's parameter and it is limited in a single operating point (not adaptable) in the BLDC motor. Therefore, in this research, an algorithm that can handle this problem is proposed. It is aimed to address the tuning problem using the optimization method and can fulfill such an objective function by optimization. Whereas to solve the second problem, adaptive PID is used. Fuzzy Logic Controller (FLC) is used to online tuning PID to cope with the system's changes. It has been proven by [8] that using FLC in PID could make the controller be able to adapt the system behavior changes.

Some methods can be used in optimization-based tunings such as GA, PSO, and ACO. A. Soundarrajan et al. [13], compare the performance of PID tuned by GA and PSO in the Automatic Voltage Regulator (AVR) system. They conclude that PID-based PSO tunings have lower settling time and overshoot. In [14], a comparative study between PID-GA and PID-PSO in an industrial process is presented. The result shows that PID-PSO has better performance both in settling time and overshoot. 
Therefore, in this research, PSO is chosen to tune PID to get an optimal PID controller.

PID, PSO, and FLC have been proposed in [11] and [15]. In [11], PSO is used to tune the FLC's scaling factor, which tunes the PID controller. Although the result shows improved performance, the online tune of PSO and FLC makes the processor working hard and cannot be implemented in a low-cost processor. In [15], PSO is used to optimize the fuzzy tuning rule, and FLC tune PID's parameters online. The result shows that the performance of the proposed controller is better than a fixed-gain PID controller. However, complex programming to optimize fuzzy membership and its rules are needed.

In this paper, optimal adaptive PI control is proposed to solve the PID problem applied in BLDC motor control which is tuning and the ability to adapt to system changes. The proposed method has an objective function to minimize control energy and maintain performance. Since some control methods give better performance with high control energy and vice versa. This objective function is like the optimal control objective function which has a trade-off between performance and control energy. However, it is implemented based on PID with a simple calculation. In an in-vehicle application, where the supply energy is only from the battery, minimum energy used in the motor means that the longer distance can be achieved.

The rest of this paper presents the BLDC motor model in Section II. Section III describes the formulation of the proposed Optimal Adaptive PI Controller. The result and discussion are elaborated in Section IV. Finally, the conclusion is provided in Section V.

\section{BLDC MOTOR MODEL}

The difference between the BLDC motor and DC motor is the addition of phases involved, which affects the overall result of the BLDC model [16], Figure 1. The mathematical model of the BLDC motor can be derived from the mathematical model of the DC motor. The BLDC motor output speed is regulated through ways of three-phase pulse-width modulation inverter. Equation (1) - (4) can express the BLDC motor equation [16]. Where $\tau_{\mathrm{m}}$ and $\tau_{\mathrm{e}}$ are mechanical and electrical time constant, respectively. The parameters of the BLDC motor model are shown in Table 1. Equation (5) shows the transfer function of the BLDC motor after all parameters' values are substituted to (4).

$$
\begin{gathered}
G(s)=\left(1 / k_{e}\right) /\left(\tau_{m} \tau_{e} s^{2}+\tau_{m} s+1\right) \\
\tau_{m}=J .3 R / k_{e} k_{t} \\
\tau_{e}=L / 3 R \\
k_{e}=k_{e(L-L)} / \sqrt{3}
\end{gathered}
$$

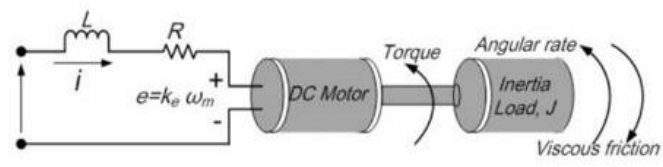

(a) DC motor

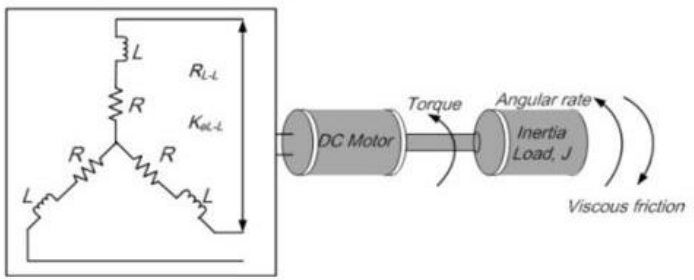

(b) BLDC motor

Figure 1. Motor Equivalent Circuit [16]

TABLE 1

PARAMETERS FOR MODELING BLDC MOTOR [16]

\begin{tabular}{|c|c|}
\hline Parameters & Values \\
\hline Motor power rating & $1.5 \mathrm{HP}$ \\
\hline Motor voltage rating $(\mathrm{V})$ & $48 \mathrm{~V}$ \\
\hline Equivalent resistance $(R)$ & $0.345 \Omega$ \\
\hline Equivalent inductance $(L)$ & $0.314 \mathrm{mH}$ \\
\hline Torque constant $(k t)$ & $4.19 \mathrm{Ncm} / \mathrm{A}$ \\
\hline Voltage constant $(k e)$ & $0.0419 \mathrm{~V} / \mathrm{rad} / \mathrm{s}$ \\
\hline Moment of inertia $(J)$ & $0.0019 \mathrm{Ncm}-\mathrm{S}^{2}$ \\
\hline
\end{tabular}

$$
G(s)=\frac{23.86}{0.00341 s^{2}+0.3019 s+1}
$$

\section{OPTIMAL ADAPTIVE PID CONTROL}

\section{A. Optimal PID Control}

Optimal PID control is PID control that must fulfill such an objective function such as in optimal control. To meet the goal of the objective function, Particle Swarm Optimization (PSO) is used to tune PID parameters. PSO was first introduced by Kennedy and Eberhart [17] which is made based on the social and communication behavior of birds. Every individual is assumed as a vector position and represents a potential solution to optimization problems. The formula for calculating speed $(V)$ and position $(X)$ is shown by (6) and (7), respectively [18].

$$
\begin{gathered}
V_{i}^{k g+1}=w(t)+V_{i}^{k g}+c_{1} r_{1}\left(p_{i}^{k g}-X_{i}^{k g}\right)+ \\
c_{2} r_{2}\left(\text { Best } S_{i}^{k g}-X_{i}^{k g}\right) \\
X_{i}^{k g+1}=X_{i}^{k g}+V_{i}^{k g}
\end{gathered}
$$

where $g=1,2, \ldots, G, i=1,2, \ldots$, population size, $r_{l}$ and $r_{2}$ is random values between $0-1, c_{1}$ is a local learning factor, $c_{2}$ is a global learning factor. Commonly, $c_{2}$ is bigger than $c_{l}$. The PSO parameters used are listed in Table 2 
TABLE 2

PSO PARAMETERS USED

\begin{tabular}{|c|c|}
\hline Parameters & Values \\
\hline$w$ & 0.2 \\
\hline$c_{1}$ & 2 \\
\hline$c_{2}$ & 2 \\
\hline Population & 25 \\
\hline Max Iteration & 10 \\
\hline Number of Variable & 2 \\
\hline Lower bound & 0 \\
\hline Upper bound & 10 \\
\hline
\end{tabular}

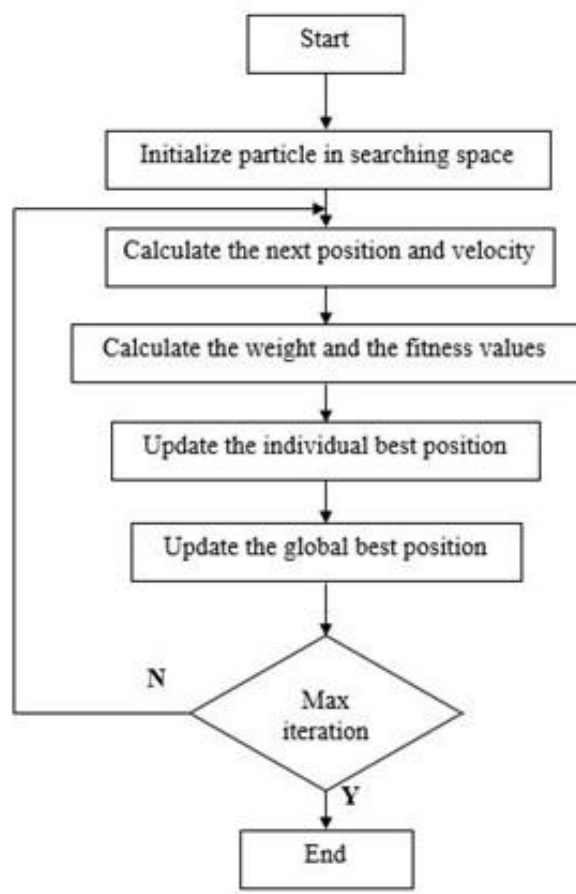

Figure 2. Flow Chart of PSO Algorithm

Figure 2 shows the flow diagram of the PSO algorithm. The objective function used in this study is the combination between Integral of Absolute Magnitude of Error (IAE), controller output $(U)$, steady-state error (SSE), and settling time (Ts) as shown in (8). Where $w_{l}$, $w_{2}, w_{3}$, and $w_{4}$ are the weighting value such that $w_{1}+w_{2}+w_{3}+w_{4}=1$. The purpose of the objective function is to get better performance from IAE, SSE, and Ts, and minimize control effort from $U$. In a physical system, the controller output is sent to the PWM generator which drives the inverter output; therefore, is proportional to the electrical energy used to drive the BLDC motor.

$$
J=\int_{0}^{\infty}\left(w_{1} I A E+w_{2} U^{2}+w_{3} S S E+w_{4} T_{S}\right)
$$

\section{B. Adaptive PID Control}

Adaptive PID control is a PID control which adaptive to the plant behavior by changing its gain value. Fuzzy Logic Controller (FLC) is a rule-based method that can be used to tune PID's parameters online base on plant behavior. FLC-PID has proven to give better performance compared to the conventional PID control as in [19]-[21]. The structure of the adaptive PID controller using FLC is shown in Figure 3.

\section{Optimal Adaptive PID Control}

Optimal adaptive PID control is the combination of optimal PID and adaptive PID. Optimal PID has the advantage to cope with the determined objective function. Whereas adaptive PID has the advantage to adapt to plant behavior changes. Therefore, combining these two methods to get PID which satisfies an objective function and adaptive to the plant changes will be done in this research.

PSO is used to tune the PID in offline mode so that the computation time not as heavy as in online tuning. Whereas the FLC is designed based on PID's parameter value from PSO. Since FLC is used to tune PID parameters, to reduce the computation time, in this research, only PI control is used. Therefore, only $K p$ and $K i$ will be tuned online. Figure 4 shows the block diagram of optimal adaptive PI control in the MATLAB/ Simulink environment. Table 3 shows the fuzzy rule which has the same rule for $K p$ and $K i$. Where, E, CE, N, Z, P are an error, change of error, negative, zero, and positive, respectively. There are two inputs namely $\mathrm{E}$ and $\mathrm{CE}$, each has three membership functions $(\mathrm{N}, \mathrm{Z}, \mathrm{P})$. The triangular membership function is chosen for both input and output because of its simplicity. Whereas the type of fuzzy used is Mamdani.

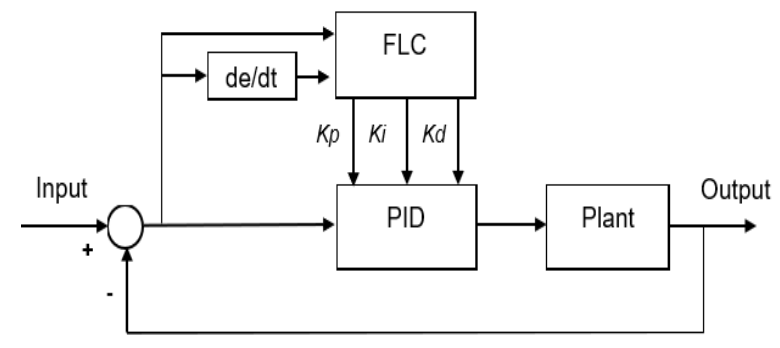

Figure 3. Block Diagram of Adaptive PID using FLC

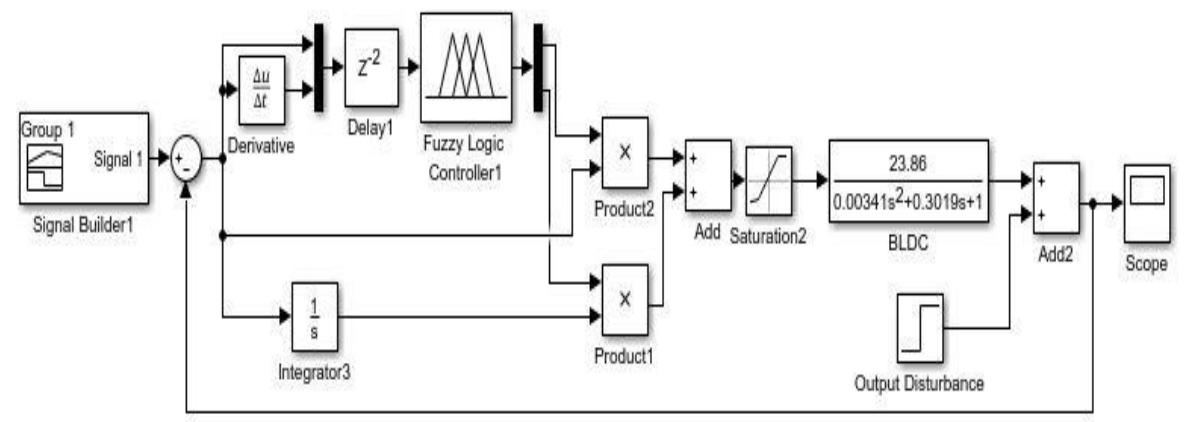

Figure 4. Simulink Block Diagram of Optimal Adaptive PI Control 
TABLE 3

FUZZY RULE FOR KP AND KI

\begin{tabular}{|c|c|c|c|}
\hline \multirow{2}{*}{$\mathbf{E}$} & \multicolumn{3}{|c|}{ CE } \\
\cline { 2 - 4 } & $\mathrm{N}$ & $\mathrm{Z}$ & $\mathrm{P}$ \\
\hline $\mathrm{N}$ & $\mathrm{M}$ & $\mathrm{M}$ & $\mathrm{M}$ \\
\hline $\mathrm{Z}$ & $\mathrm{Z}$ & $\mathrm{Z}$ & $\mathrm{Z}$ \\
\hline $\mathrm{P}$ & $\mathrm{B}$ & $\mathrm{B}$ & $\mathrm{B}$ \\
\hline
\end{tabular}

\section{RESUlt AND DisCUSSION}

Two algorithms are tested and compared with the proposed algorithm which is PI (tuned manually) and Optimal PI (named as PI-PSO since PSO is used to tune $\mathrm{PI})$. Whereas the proposed algorithm is Optimal Adaptive PI control which combines PI-PSO with FLC called PIPSO-FLC. The value of $K p$ and $K i$ for all methods are listed in Table 4. Both performance and control efforts $(U)$ are compared. Performance is represented by settling time $\left(T_{s}\right)$, Overshoot/ Undershoot, and IAE. Figure 5 shows the flow chart of the control design and optimization process. It is seen that the PSO algorithm used for PI-PSO and PI-PSO-FLC are the same, the only difference is the use of FLC in the second method.

Three condition testing is carried out which are step response, set-point changes, and disturbance rejection in one simulation result. Total simulation time is 5 seconds where step response testing is between 0 to 2 seconds. Set-point changes from 2 to 3.6 seconds and the last test is 3.6 until the end of simulation time. In this test, the tolerance of $\pm 1 \%$ is used. The simulation result can be seen in Figure 6 and the detailed result is summarized in Table 5.

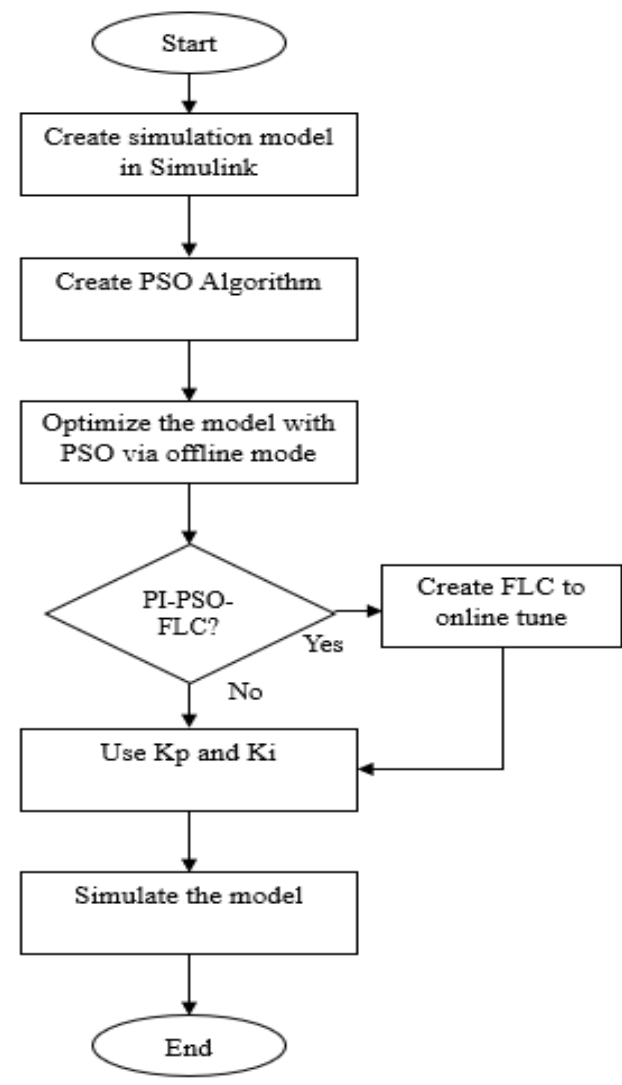

Figure 5. Control Design and Optimization Process
TABLE 4

KP AND KI VALUE

\begin{tabular}{|l|c|c|}
\hline \multicolumn{1}{|c|}{ Method } & $\boldsymbol{K} \boldsymbol{p}$ & $\boldsymbol{K i}$ \\
\hline PI & 0.05 & 0.44 \\
\hline PI-PSO & 0.6 & 1.2 \\
\hline PI-PSO-FLC & $0.1-1.1$ & $1-1.4$ \\
\hline
\end{tabular}

TABLE 5

RESUME OF TESTING RESULT

\begin{tabular}{|c|c|c|c|c|}
\hline Method & $\begin{array}{c}\text { Settling } \\
\text { time }(T s)\end{array}$ & $\begin{array}{c}\text { Max \% } \\
\text { overshoot/ } \\
\text { undershoot }\end{array}$ & IAE & $\int U^{2} d t$ \\
\hline \multicolumn{5}{|l|}{ Step response } \\
\hline PI & 0.86 & $13 / 0$ & 0.1896 & 0.0044 \\
\hline PI-PSO & 0.57 & $3 / 3$ & 0.0363 & 0.0095 \\
\hline PI-PSO-FLC & 0.14 & $0 \quad / 0$ & 0.0393 & 0.0067 \\
\hline \multicolumn{5}{|c|}{ Set-point changes } \\
\hline PI & 2.86 & $\begin{array}{ll}0 & / 7\end{array}$ & 0.2844 & 0.0050 \\
\hline PI-PSO & 2.08 & $0 \quad / 2$ & 0.0539 & 0.0112 \\
\hline PI-PSO-FLC & 2.11 & $0 \quad / 0$ & 0.0598 & 0.0076 \\
\hline \multicolumn{5}{|c|}{ Disturbance rejection } \\
\hline PI & 4.44 & $0 \quad / 6$ & 0.3599 & 0.0050 \\
\hline PI-PSO & 3.68 & $0 \quad / 2$ & 0.0685 & 0.0121 \\
\hline PI-PSO-FLC & 3.70 & $0 \quad / 0$ & 0.0766 & 0.0080 \\
\hline
\end{tabular}

Step responses are the basic testing to know the performance of the controller including settling time and overshoot/ undershoot. In this condition of testing, PIPSO-FLC has the best performance responses both in settling time and overshoot. PI-PSO is in second place with better settling time compared to PI. However, it still has a small overshoot and undershoots. In terms of IAE, PI-PSO has the smallest value since it has the fastest rise time, whereas the proposed method is in second place since it has a longer rise time. In terms of control effort, PI has the lowest control effort because its response is the slowest, followed by PI-PSO-FLC, and PI-PSO in the last place. The higher control effort, the faster time response of the systems.

The second test is set-point changes. In this test, PI has the lowest control effort, PI-PSO is superior in terms of settling time and IAE, whereas PI-PSO-FLC has no overshoot/undershoot. In terms of settling time, the proposed method is faster than PI, hence it has the same result as PI-PSO-FLC by lower IAE. However, it has a moderate control effort as seen in Table 5.

The last test is disturbance rejection. In this test, the impulse disturbance is given at time 3.6 seconds with amplitude 0.4. This test gives the same result as the second test, where PI has the worst parameter value except in control effort. PI-PSO is dominant in settling time and IAE. However, it has a small overshoot with the highest control effort. The proposed method has no overshoot/undershoot. Figure 7 shows the PI parameter changes in Optimal Adaptive PI control. It is seen that the $K p$ and $K i$ changes where the system condition varies, for example, step responses, set-point changes, and disturbance.

The IAE and integral of control effort are calculated from the beginning until the end of simulation; therefore, from the final values of it, the performance and control effort can be compared. The proposed method has lower IAE and higher control effort by $78.73 \%$ and $60 \%$ compared to PI control. On the other hand, it has a higher IAE dan lower control effort by $11.82 \%$ and $33.88 \%$ 
compared to PI-PSO. The PI-PSO-FLC has higher control effort compared to PI control because its gain varies according to the system condition; therefore, sometimes it has a higher gain which makes it consume more energy. On the other side, its IAE is higher than PIPSO, since when it adapts to system changes, the lower gain makes it longer to reach the set-points.

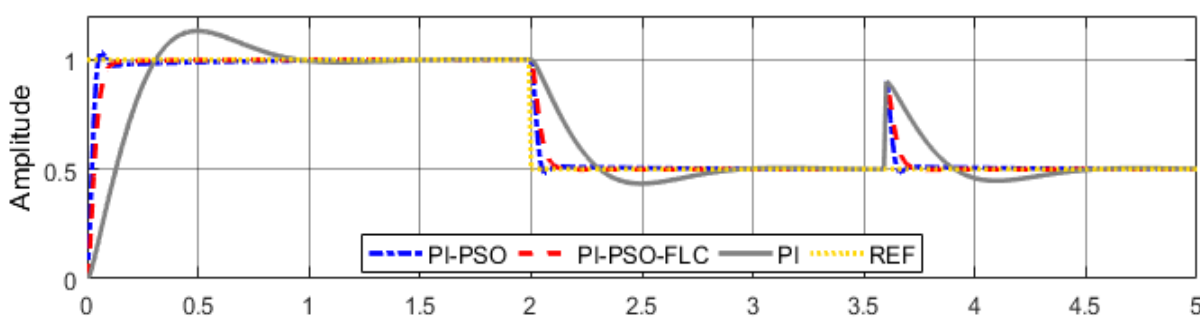

(a)

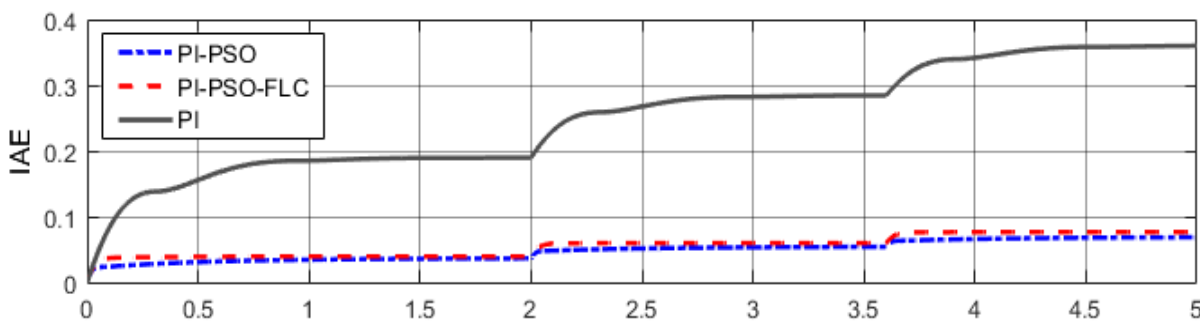

(b)

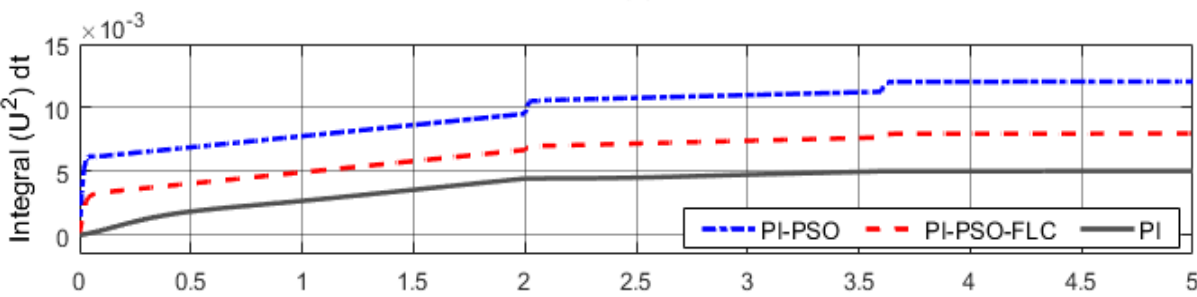

(c)

Time (second)

Figure 6. Simulation Result (a) Speed Profile (b) IAE Profile (c) Integral of The Square of Control Effort Profile

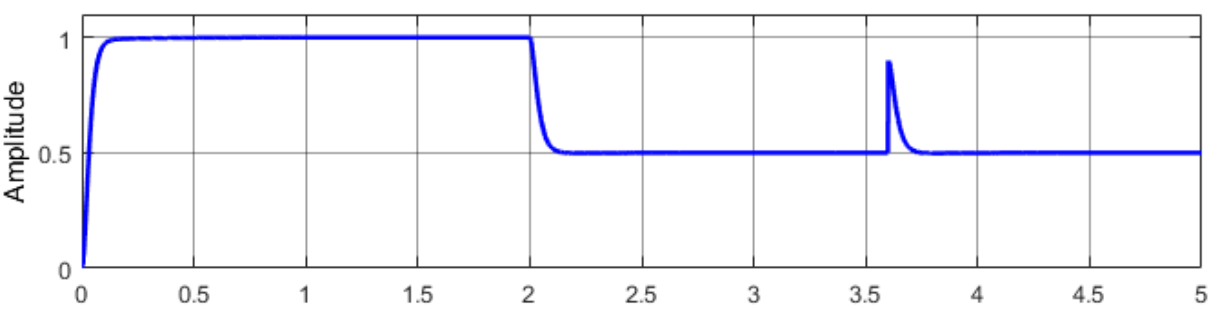

(a)

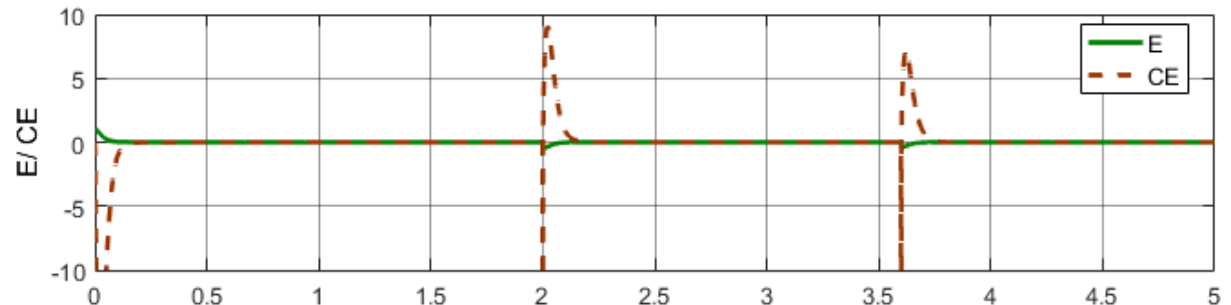

(b)

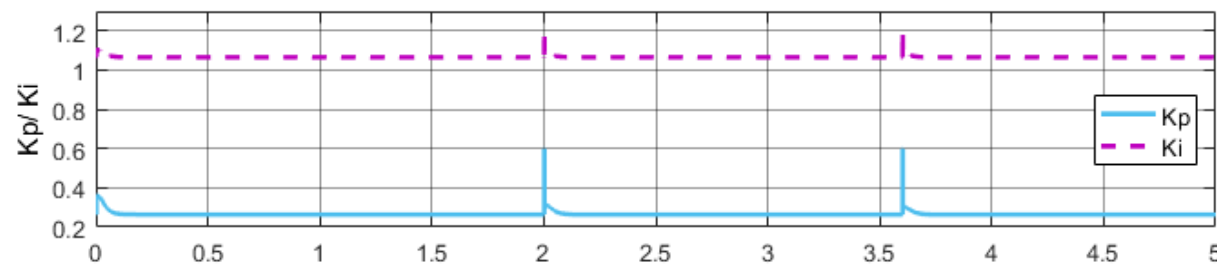

(c)

Time (second)

Figure 7. Optimal Adaptive PID (a) Speed Profile (b) Input to The Fuzzy System (c) Output of The Fuzzy System 


\section{CONCLUSION}

The proposed algorithm is simple and easy to be implemented because it is based on the PID algorithm. It was successfully implemented in the simulation environment. It also can be implemented in a low-cost industrial processor because the optimization is done offline while the FLC is made with simple rules. The test was carried out in three conditions whereas step responses, set-point changes, and disturbance rejection. The proposed algorithm is superior with no overshoot/undershoot. Whereas in terms of settling time, our proposed method is in between PI and PI-PSO. PI controller has the smallest control effort. However, the other parameters of PI are the worst. PI-PSO is superior in terms of settling time and IAE except for the step response test. The proposed method has lower IAE and higher control effort by $78.73 \%$ and $60 \%$ compared to PI control. On the other hand, it has a higher IAE dan lower control effort by $11.82 \%$ and $33.88 \%$ compared to PI-PSO. Therefore, the optimal adaptive PI control can reduce energy consumption compared to optimal PI and with better performance compared to PI control.

\section{ACKNOWLEDGMENT}

This research is the collaboration between Universitas Sultan Ageng Tirtayasa (UNTIRTA) and Sebelas Maret University (UNS), funded by the Ministry of Education and Culture of the Republic of Indonesia.

\section{REFERENCES}

[1] S. M. Rakhtala and E. S. Roudbari, "Application of PEM fuel cell for stand-alone based on a fuzzy PID control," Bulletin Elect. Eng. Informatics, vol. 5, no. 1, pp. 45-61, 2016.

[2] K. H. Ang, G. Chong, and Y. Li, "PID control system analysis, design, and technology," IEEE Trans. Control Syst. Technol., vol. 13, no. 4, pp. 559-576, 2005.

[3] A. Balestrino, A. Caiti, V. Calabró, E. Crisostomi, and A. Landi, "From basic to advanced PI controllers: a complexity vs. performance comparison," in Advances in PID Control, UK: InTech, 2011, pp. 85-100

[4] A. Y. Jaen-cuellar, R. de J. Romero-Troncoso, L. Moralesvelazquez, and R. A. Osornio-rios, "PID-Controller tuning optimization with genetic algorithms in servo systems," Int. J. Adv. Robot. Syst., vol. 10, pp. 1-14, 2013.

[5] J. M. Herrero, X. Blasco, M. Martinez, and J. V Salcedo, "Optimal PID tuning with genetic algorithms for non linear process models," in 15th Triennial World Congr., 2002, pp. 31-36.

[6] A. A. M. Zahir, S. S. N. Alhady, W. A. F. W. Othman, and M. F. Ahmad, "Genetic algorithm optimization of PID controller for brushed DC motor," Intell. Manuf. Mechatron., pp. 427-437, 2018.

[7] C. Lin, H. Jan, and N. Shieh, "GA-based multiobjective PID control for a linear brushless DC motor," IEEE/ASME Trans. Mechatron., vol. 8, no. 1, pp. 56-65, 2003.

[8] R. Arulmozhiyal and R. Kandiban, "Design of fuzzy PID controller for brushless DC motor," in 2012 Int. Conf. Comput. Commun. Informat., 2012.

[9] M. A. Ibrahim, A. K. Mahmood, and N. S. Sultan, "Optimal PID controller of a brushless DC motor using genetic algorithm," Int. J. Power Electron. Drive Syst., vol. 10, no. 2, pp. 822-830, 2019.

[10] L. Harnefors, S. E. Saarakkala, and M. Hinkkanen, "Speed control of electrical drives using classical control method," IEEE Trans. Ind. Applicat., vol. 49, no. 2, pp. 889-898, 2013.

[11] S. Lin and G. Wang, "Fuzzy PID control algorithm based on PSO and application in BLDC motor," in 3rd Int. Conf. Advances Energy Environment Chemical Eng., 2017.

[12] N. N. Baharudin and S. M. Ayob, "Brushless DC motor speed control using single input fuzzy PI controller," Int. J. Power Electron. Drive Syst., vol. 9, no. 4, pp. 1952-1966, 2018.

[13] A. Soundarrajan, S. Sumathi, and C. Sundar, "Particle swarm optimization based LFC and AVR of autonomous power generating system," IAENG Int. J. Comput. Sci., vol. 37, no. 1, 2010.

[14] M. E. El-Telbany, "Employing particle swarm optimizer and genetic algorithms for optimal tuning of PID controllers: a comparative study," ICGST-ACSE J., vol. 7, no. 2, pp. 49-54, 2007.

[15] C. Ko and C. Wu, "A PSO-Tuning method for design of fuzzy PID controllers," J. Vibration Control, vol. 14, no. 3, pp.375-395, 2008.

[16] E. Gowthaman, V. Vinodhini, M. Y. Hussain, S. K. Dhinakaran, and T. Sabarinathan, "Speed control of permanent magnet brushless DC motor using hybrid fuzzy proportional plus integral plus derivative controller," in Energy Procedia, vol. 117, pp. 1101-1108, 2017.

[17] S. K. Injeti and M. Divyavathi, "Optimal gain scheduling of PID controller for the speed control of PMSM drive using bio-inspired optimization algorithms," Int. J. Elect. Eng. Informat., vol. 11, no. 2, pp. 308-325, 2019.

[18] A. Maarif, H. Nabila, Iswanto, and O. Wahyunggoro, "Application of intelligent search algorithms in proportionalintegral- derivative control of direct-current motor system," $J$. Physics Conf. Series, vol. 1373, 2019.

[19] U. K. Bansal and R. Narvey, "Speed control of DC motor using fuzzy PID controller," Adv. Electron. Electr. Eng., vol. 3, no. 9, pp. 1209-1220, 2013.

[20] C. Conker and M. K. Baltacioglu, "Fuzzy self-adaptive PID control technique for driving $\mathrm{HHO}$ dry cell systems," Int. J. Hydrogen Energy, vol. 45, no. 49, pp. 26059-26069, 2020.

[21] N. P. Ananthamoorthy and K. Baskaran, "High performance hybrid fuzzy PID controller for permanent magnet synchronous motor drive with minimum rule base," J. Vibration Control, vol. 21, no. 1, pp. 181-194, 2013. 